DOI 10.15393/j9.art.2018.5301

УДК 821.161.1.09“18”

Аркадий Николаевич Неминущий

(Даугавпилс, Латвия)

arkadij05@inbox.Iv

\title{
Структура и функции звукового кода в «Записках охотника» И. С. Тургенева
}

Аннотация. Исследователи творчества И. С. Тургенева на сегодняшний день накопили значительный опыт изучения и интерпретации семантики различных компонентов художественного мира писателя. В течение долгого времени основное внимание было сконцентрировано на проблемах выявления особенностей воссоздания героев и персонажей тургеневской прозы. Вместе с тем во второй половине XX в. значительные усилия предпринимались для определения места и функций пространственно-временной организации, ее визуального (в том числе колористического) сегмента, а также особенностей сферы ольфакции. Однако роль звуковой партитуры в границах поэтики Тургенева изучалась только эпизодически. Между тем звуковой код в цикле «Записки охотника» имеет большое значение. Структура данного компонента общей картины мира представляет собой несколько уровней, внутри которых присутствует определенная иерархия. На природном уровне доминируют звуки фауны с преобладанием голосов птиц, что транслирует семантику воздушной стихии и свободы. Шумовой элемент изображенной флоры строится на пантеистических принципах с акцентом на эстетизацию и метафоризацию. В рамках социального звукового кода особое место занимает культурная парадигма с четко выделенным музыкальновокальным рядом, который складывается в особый сюжет с кульминацией в рассказе «Певцы». Наконец, ряд «мистических» звуков дополняет сложную картину национального космоса, каким его воспринимает и изображает Тургенев в своем прозаическом цикле.

Ключевые слова: Тургенев, «Записки охотника», фоносфера природы, звуки социума, звуковой код культуры

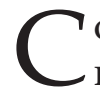

о времени выхода в свет тургеневский цикл «Записки охотника» постоянно находился и находится в сфере активного внимания литературных критиков и ученых-филологов. За более чем полуторавековой период один из первых прозаических опытов писателя был исследован в самых разных аспектах. При этом достаточно четко выделилась общая тенденция - переход от попыток осмысления идейной, концептуальной (включая 
социальную) проблематики, специфики воссоздания героев и персонажей к изучению особенностей эстетики, поэтики и семантики значимых параметров художественного мира «Записок», что было реализовано усилиями А. И. Батюто, С. Е. Шаталова, А. Б. Муратова, Г. Б. Курляндской, Ю. В. Лебедева и других авторитетных тургеневедов, начиная со второй половины XX в. Впрочем, сказанное можно отнести не только к «Запискам охотника», но и ко всему творчеству И. С. Тургенева.

Именно этот поворот сделал актуальным анализ компонентов, воссоздающих внутренний мир тургеневских текстов, причем приоритетный интерес исследователей был сосредоточен уже не только на проблеме героя, но и на выявлении своеобразия пространственно-временной организации [Гареева: 33-39], [Логутова: 23-41], а из более локальных уровней - колористической и свето-теневой гаммы пейзажных и иных описаний [Бурштинская: 3-17]. Несколько позже были предприняты попытки осмысления места и функций ольфакторной составляющей в поэтике прозы Тургенева [Зыховская, 2014: 63-65], [Зыховская, 2016: 300-349], [Рогачева, Хуэйсинь Цзи: 80-93]. Фоносфера как еще один из атрибутов художественного мира писателя являлась объектом изучения лишь эпизодически [Кривонос: 32-37], [Плесканюк: 53-56], что в полной мере распространяется и на «Записки охотника».

Для того чтобы дать корректную оценку структуры и семантики звукового кода в тургеневском цикле необходимо учесть несколько важных обстоятельств. Одно из них - пространственные координаты, воссоздающие в «Записках охотника» мир природы, локусы деревни, усадьбы и соединяющей их дороги [Макарова: 179-182]. Хотя в цикле упоминаются уездные и губернские города, звуки урбанистической цивилизации никак не обозначены.

Кроме того, нельзя не учитывать родовую и жанровую принадлежность текстов, составивших «Записки». Так, скажем, эпический характер прозы, особенно в рамках реалистического типа художественного мышления сам по себе предполагает максимальную полноту воссоздания действительности, однако жанровые рамки малой повествовательной формы неизбежно ограничивают потенциальные возможности автора 
в этом плане. Кстати, дискуссии о жанровом своеобразии цикла в целом и его отдельных элементов имеют давнюю историю и продолжаются до сих пор. Большинство исследователей склоняются к тому, что формат очерка, ориентированного на эстетику «натуральной школы» с установкой на «копирование» реальности не может быть соотнесен с большинством опытов Тургенева в пределах цикла (см., напр.: [Беляева: 55-59], [Толоконникова: 17-24]). Как минимум макротекст в целом и его отдельные компоненты можно оценить в качестве полижанрового явления с ориентацией на рассказ, новеллу и даже повесть [Фуникова: 176-179], а в отдельных случаях и контаминацию всех указанных вариантов.

Наконец, важным представляется определение своеобразия рецепции звукового ряда в границах художественного мира «Записок», в том числе выявление субъекта восприятия фоносферы и последующего ее отображения. Всеобъемлющая категория автора требует в данном случае конкретизации и детализации. Долгое время преобладавшая точка зрения, которая представляла в качестве основного субъекта речи и сознания героя-рассказчика (охотника), в последние годы критически переосмыслена. Так, например, по мнению В. А. Кошелева, рассказчик именно как персонаж заявлен в текстах цикла только номинально и зачастую не совпадает с декларированными границами его «Я» [Кошелев: 103-108]. На самом деле «событие рассказывания» развернуто в «Записках» многообразно: статус носителя речи имеет «мерцающий» характер, он может быть связан с персонифицированным рассказчиком, ограниченном в плане возможностей созерцания и слушания, иногда перевоплощающимся в пересказчика чужих жизненных историй с включением в них и звукового компонента. Рассказчик же в отдельных случаях приобретает статус повествователя с отсутствием привязки к конкретному топосу [Кривонос: 298-311]. В конце концов, либо рассказчик, либо повествователь, максимально близкий уже к собственно автору, может передоверять функцию слушания отдельным персонажам, что мультиплицирует количество потенциальных слуховых каналов, делая процесс восприятия окружающего мира не монопольно 
индивидуальным, но коллективным, как это происходит, например, в рассказе «Бежин луг».

Не стоит забывать и о том, что устойчиво доминирующим принципом художественного воссоздания мира в прозе Тургенева является визуализация, все остальные элементы поэтики заявлены как подчиненные (см. об этом: [Турбанов: 213-305]).

Тем не менее следует отметить, что фоносфера в «Записках охотника» (если вывести за скобки безальтернативно звучащий речевой компонент в монологах, диалогах и полилогах персонажей) при неизбежной селективности так или иначе представляет значимые области бытия: природную (в ее живом и неживом вариантах), человеческую и социальную с встроенной в них определенной иерархией.

Так, среди звуков фауны безусловно преобладают голоса «птичьего царства», которые занимают в воссозданном природном сегменте весьма существенное место. Уже во втором рассказе цикла - «Ермолай и мельничиха» - представлена связанная с пернатыми развернутая «звуковая панорама» вечернего леса:

«Горихвостки, маленькие дятли <...> сонливо посвистывают... $<\ldots>$ Еще раз прозвенел над вами звонкий голос пеночки; где-то печально прокричала иволга, соловей щелкнул в первый раз. $<\ldots>$... вдруг в глубокой тишине раздается особого рода карканье и шипенье, слышится мерный взмах проворных крыл, и вальдшнеп, красиво наклонив свой длинный нос, плавно вылетает из-за темной березы» ${ }^{1}$.

Повествователь (в данном случае скорее рассказчик в статусе знатока-охотника) демонстрирует способность уверенно различать крики разных птиц, но избегает полноформатных описаний или звукоподражания. Возможность же «аудиореконструкции» адресуется к сфере компетенции потенциального читателя или способностям его воображения. Еще один образец уже дневной орнитологической шумовой панорамы, настоящего птичьего хора встречается в рассказе «Смерть», где в одном предложении сведены упоминания о свистящих ястребах, кобчиках и пустельгах, стучащих по крепкой коре пестрых дятлах, звучном напеве черного дрозда, переливчатом крике иволги, чирикании и пении малиновки, чижей и пеночек. 
Впрочем, приведенные примеры скорее исключение. Чаще Тургенев ограничивается только номинацией звуков либо их кратким описанием в пределах словосочетания. Так, в разных текстах представлены птичьи голоса каркающих воронов, болтающих скворцов, воркующих голубей, звонкое посвистывание ласточек, чириканье воробьев, шум крыльев диких уток и т. п.

Заметно уступают по частоте упоминаний «шумовые эффекты» одомашненных птиц: только однажды номинируется пение канарейки, несколько раз «квохтание» и «крехтание» кур, крик петуха, «беспрестанная перекличка» индеек.

Такой минимализм вполне объясним. Пространственная позиция рассказчика фиксируется в основном на лоне дикой, часто свободной от человеческого присутствия природы, к тому же в динамической смене мест пребывания, а дом, будь это крестьянский двор, деревня или дворянская усадьба только временное пристанище, что и определяет столь небогатый репертуар звукового кода в этой нише.

Заслуживает внимания еще один феномен: в отличие от тварей небесных голоса земных существ, причем независимо от того дикие они или домашние, также представлены как факультативные, а то и вовсе отсутствуют. Так, например, никак себя не обозначают в рассматриваемом аспекте лесные звери, разве что насекомые избирательно включаются в совокупный аудиопоток. В отличие от преимущественно объективной фиксации птичьих трелей и рулад звуки насекомых нередко сопровождаются оценочными суждениями персонифицированного рассказчика с очевидно негативной семантикой: однообразное жужжание и гудение пчел, стрекот сверчков, треск кузнечиков явно не вызывают позитивного восприятия, что особенно активно выражено в рассказе «Касьян с Красивой Мечи»: «Одни кузнечики дружно кричат, словно озлобленные, - и утомителен этот непрестанный, кислый и сухой звук» (114).

Не обойдены вниманием рассказчика или повествователя домашние животные, среди которых наверху условной иерархической лестницы располагаются лошади и собаки, хотя присутствие их голосов и шумов также находится на периферии общего звукового потока. Упоминаемые лошадиное ржание 
и топот копыт, собачий лай и визг, мычание коров, «задумчивое хрюканье» свиньи и т. п. чаще всего безальтернативно обозначают присутствие рассказчика в конкретном локусе, усиливая в некоторых случаях очерковый характер повествования.

Природный мир в части флоры также имеет свое шумовое оформление, причем способы его презентации несколько отличаются. С одной стороны, воспроизводятся особенности восприятия все того же знатока и вдумчивого наблюдателя, как это сделано, к примеру, в рассказе «Свидание»:

«Листья чуть шумели над моей головой; по одному их шуму можно было узнать, какое тогда стояло время года. То был не веселый, смеющийся трепет весны, не мягкое шушуканье, не долгий говор лета, не робкое и холодное лепетанье поздней осени, а едва слышная, дремотная болтовня» (240).

С другой стороны, в приведенном образце присутствует явная метафоризация и эстетизация природного феномена. Такое пантеистическое видение актуализируется практически во всех случаях упоминаний растительных шумов: это «болтливый лепет листьев», «шуршание камышей», «бушующие под порывами ветра» верхушки деревьев и т. п.

Полнота звуковой картины природного мира обеспечивается упоминаниями о шуме дождя, порывах ветра, громовых раскатах, плеске и журчании воды. В центре этого звукового поля, разумеется, находится человек, а точнее, герой или персонаж очерков и рассказов. Виды человеческой активности, инициирующие тот или иной вид звукопорождения, также многообразны.

Следует отметить, что звуковой ряд, связанный с трудовой деятельностью и бытовой сферой социума при всей реалистичности, а иногда даже натуралистичности некоторых описаний, занимает весьма скромное место. Так, например, только в нескольких рассказах упомянуты звуки ударов топора во время рубки леса и выстрелы охотников. Быт в фонетическом аспекте представлен разве что в «Гамлете Щигровского уезда», где герой вспоминает о хлопающих пробках шампанского во время холостяцкого обеда и лапидарно описывает ритуал чаепития: «...самовар затейливо шипел, 
словно чему-то радовался; с веселым треском ломались крендельки, ложечки звонко стучали по чашкам» (268).

Самый же значимый сегмент звукового кода, связанного в «Записках охотника» с человеком, относится к сфере культуры, и более конкретно - музыки и пения, причем репертуар упомянутых в расчете или на реконструкцию в сознании читателя или описанных в каком-то варианте феноменов такого рода представлен с поистине впечатляющей полнотой. Музыкальный и вокальный «каталог» «Записок» включает явно доминирующие в нем народные песни различных жанров (см. об этом: [Быкова: 110-114], [Петерс: 18-25]), а также романсы русских композиторов М. И. Глинки, А. Е. Варламова, А. Л. Гурилева и «какой-то французский романс», пафосный музыкальный дифирамб «Гром победы раздавайся» авторства О. И. Козловского и Г. Р. Державина, цыганские песни, «страстно задумчивую фразу из Бетховена», оперы «Лючия ди Ламмермур» Г. Доницетти и «Сомнамбула» В. Беллини.

Такая музыкальная наполненность впервые встречается именно в «Записках охотника» и сохраняется у Тургенева в дальнейшем. Можно согласиться с Г. Л. Ачкасовой, отмечавшей важность этого компонента в более позднем творчестве писателя: «...его герои слушают музыку, говорят о музыке, музицируют сами. Есть такие <произведения>, в которых музыка становится реально действующим персонажем, способным преображать, пусть ненадолго, действительность» [Ачкасова: 354].

Функции музыкально-вокального кода в «Записках» достаточно многообразны. Возможно, самая очевидная из них быть средством маркировки персонажей по социальному и культурному признаку. Так, скажем, действующие лица благородного происхождения слушают или воспроизводят возвышенную музыку (хотя встречаются исключения, как в случае с дворянином Чертопхановым, который с восторгом внимает цыганским напевам своей возлюбленной Маши, или помещиком Радиловым, обожающим плясовые мелодии), народные же песни - исключительная прерогатива представителей социальных низов.

Именно музыка нередко становится одним из способов тех или иных характеристик, а в некоторых случаях прямых оценок 
персонажей, причем те из них, которые представляют социальные верхи, как правило, демонстрируют явно не лучшие личностные качества. Можно вспомнить, к примеру, напевающего какой-то французский романс рафинированного садиста Аркадия Павлыча Пеночкина из рассказа «Бурмистр». Особенно показателен в этом смысле рассказ «Татьяна Борисовна и ее племянник». Последний из упомянутых в названии персонажей часто занимает себя музицированием, но в очень своеобразном, карикатурном варианте:

«Сядет, бывало, за фортопьяны (у Татьяны Борисовны и фортопьяны водились) и начнет одним пальцем отыскивать “Тройку удалую”; аккорды берет, стучит по клавишам; по целым часам мучительно завывает романсы Варламова: "У-единенная сосна" или "Нет, доктор, нет, не приходи”, а у самого глаза заплыли жиром и щеки лоснятся, как барабан... А то вдруг грянет: "Уймитесь, волнения страсти”... Татьяна Борисовна так и вздрогнет. <...>

“Я стра-ажду, я стра-ажду", - завыл в соседней комнате племянник.

- Полно тебе, Андрюша.

“Душа изнывает в разлу-уке”, - продолжал неугомонный певец» (194-195).

Уничижительно оценивается еще один исполнитель, «некий дюжий парень с гитарой» (вероятнее всего, из господской дворни) в рассказе «Контора». Явно пытаясь придать себе в восприятии слушателей более высокий статус, он напевает известный романс «Я в пустыню удаляюсь» в претенциозной, пошло-лакейской манере:

«Э - я фа пустыню удаляюсь

Ата прекарасаных седешенеха мест...» (141).

Человек, воспроизводящий народные мелодии и напевы, напротив, никогда не изображается в негативном аспекте. Такая музыка становится средством выражения подлинных эмоций, иногда страстей, вообще какого-то значимого психологического состояния персонажа, наконец, того, что можно определить как «национальный дух».

Кроме того, музыкальный код внутри цикла складывается в некий относительно самостоятельный сюжет с явно продуманной композицией. Точкой отсчета становится дуэт Хоря 
и Калиныча из одноименного очерка, которые в сопровождении балалайки поют печальную «Доля ты моя, доля!», а завершается этот ряд минорно-просветленной «Во лузях», исполняемой едва ли не в последние часы жизни умирающей Лукерьей из рассказа «Живые мощи».

Внутри этой сюжетной линии представлено сложное чередование музыки, объективно принадлежащей к высокой культуре, и контрастных по звучанию веселых народных песен, плясовых вроде «Как у наших у ворот», «Ай, жги, говори» и тех, которые можно собирательно характеризовать как «переливчатый, однообразный, безнадежно-скорбный напев» (106). Своеобразным апофеозом, где сходятся обе версии музыкального фольклора, безусловно, становится рассказ «Певцы» с коллизией состязания двух исполнителей. Здесь единственный раз во всем цикле с максимальной полнотой представлено описание звучащих мелодий. Тургенев воссоздает здесь своеобразный «экфрасис», пытаясь материализовать в слове особенности звучания голосов и эмоциональное содержание пения рядчика и Якова Турка:

«...рядчик выступил вперед, закрыл до половины глаза и запел высочайшим фальцетом. Голос у него был довольно приятный и сладкий, хотя несколько сиплый; он играл и вилял этим голосом, как юлою, беспрестанно заливался и переливался сверху вниз и беспрестанно возвращался к верхним нотам...» (219).

И далее:

«...Яков открыл свое лицо - оно было бледно, как у мертвого; глаза едва мерцали сквозь опущенные ресницы. Он глубоко вздохнул и запел... Первый звук его голоса был слаб и неровен и, казалось, не выходил из его груди, но принесся откуда-то издалека, словно залетел случайно в комнату. <...> За этим первым звуком последовал другой, более твердый и протяжный, но все еще видимо дрожащий, как струна, когда, внезапно прозвенев под сильным пальцем, она колеблется последним, быстро замирающим колебаньем, за вторым - третий, и, понемногу разгорячаясь и расширяясь, полилась заунывная песня» (221-222).

В данном случае не менее важна и столь же подробно воспроизведенная реакция слушателей, которая включает целый набор на первый взгляд взаимоисключающих эмоций - от 
экстатического восторга по поводу исполненной рядчиком плясовой мелодии до глубочайшего потрясения, внешне выраженного слезами и даже рыданиями. Причина такого восприятия пения, одержавшего победу в состязании Якова, определена рассказчиком вполне внятно: «Русская правдивая, горячая душа звучала и дышала в нем и так и хватала вас за сердце, хватала за его русские струны» (222).

Наконец, нельзя обойти вниманием еще одну группу звуков, составляющих фоносферу «Записок охотника», которая включает в себя звуки странные, таинственные, трудно или вообще необъяснимые с рациональной точки зрения, в отдельных случаях почти мистические, по крайней мере, в повествовательной препозиции. Этот ряд наиболее заметно представлен в рассказах «Бежин луг», «Живые мощи» и «Стучит».

Так, например, в первом из упомянутых текстов один из крестьянских мальчиков рассказывает у ночного костра историю о том, как проходя мимо «бучила» услышал оттуда непонятный жалостливый голос, который страшно его напугал. Несколько позже все действующие лица, включая рассказчика, улавливают «странный, резкий, болезненный крик» над рекой. Показательно, что определить его источник не может в данной ситуации, казалось бы, опытный рассказчик-охотник - распознает же в этом крике голос цапли мальчик Павлуша.

Вообще в «Бежином луге» количество звуков, не опознаваемых, по крайней мере, в момент их восприятия, отличается изощренным разнообразием. В некоторых случаях они получают постповествовательное объяснение, но далеко не всегда. К таким относится, например, «протяжный, звенящий, почти стенящий звук, один из тех непонятных ночных звуков, которые возникают иногда среди глубокой тишины, поднимаются, стоят в воздухе и медленно разносятся, наконец, как бы замирая» (95).

Аудиообозначения в рассказе «Стучит», где звук бубенцов и стук колес неотвратимо преследующей рассказчика и его возницу на пустынной ночной дороге разбойничьей тройки, можно оценить как почти символический маркер внушающей ужас субстанции бытия, чреватого внезапными, гибельными поворотами судьбы. И, напротив, совершенно иной смысл несет упоминание о колокольном звоне, идущем «как бы сверху», который слышит в день своей кончины праведница Лукерья из рассказа «Живые мощи», причем попытка рациональной 
характеристики источника раздающихся звуков почти сразу нейтрализуется, поскольку рассказчик сообщает о том, что до церкви было не менее пяти верст и день был будничный.

Подводя итог можно констатировать, что звуковой код в «Записках охотника» составляет важную и насыщенную смыслами часть общей картины мира. Разумеется, он не реализуется изолированно, входит в сложное, «синэстетическое» (по терминологии В. Н. Топорова) [Топоров: 53] единство национального космоса, каким его видит и воссоздает Тургенев. Освоенные в цикле принципы организации архитектоники художественного мира будут использованы в более поздних по времени создания прозаических опытах писателя.

\section{Примечания}

1 Тургенев И. С. Полн. собр. соч. и писем: в 30 т. М.: Наука, 1979. Т. 3 : Сочинения. С. 19. Далее ссылки на это издание приводятся в тексте статьи с указанием страницы в круглых скобках.

\section{Список литературы}

1. Ачкасова Г. Л. Диалог искусств как способ раскрытия художественной индивидуальности писателя: союз слова и музыки в творчестве И. С. Тургенева // Ученые записки Российского государственного социального университета. - 2011. - № 6. - С. 353-357.

2. Беляева И. А. Система жанров в творчестве И. С. Тургенева. - М.: МГПУ, 2005. - $252 \mathrm{c}$.

3. Бурштинская Е. А. Цвет как аспект литературного портрета в художественной прозе И. С. Тургенева: автореф. дис. ... канд. филол. наук. Череповец, 2000. - $18 \mathrm{c}$.

4. Быкова О. С. Народные песни в «Записках охотника» и повести «Затишье» И. С. Тургенева // Русская речь. - 2018. - № 1. - С. 107-114.

5. Гареева Л. Н. Функции пейзажа в романах И. С. Тургенева «Дворянское гнездо» и «Накануне» // Вестник ВГУ. Серия: Филология. Журналистика. - Воронеж, 2012. - № 1. - С. 33-39.

6. Зыховская Н. Л. Запах как принцип «художественного досье» в прозе Тургенева // Путь науки. - Волгоград, 2014. — № 6. - С. 63-65.

7. Зыховская Н. Л. Ольфакторий русской прозы XIX века: дис. ... д-ра филол. наук. - Екатеринбург, 2016. - 518 с.

8. Кошелев В. А. Эффект охотника в русской словесности середины XIX века // И. С. Тургенев. Новые исследования и материалы. - М.; СПб.: Альянс-Архео, 2009. - С. 95-111.

9. Кривонос В. Ш. Мотив стука в поэтике И. С. Тургенева // Известия Академии наук. Серия литературы и языка. — 2000. - Т. 59. — № 5. — С. 32-37. 
10. Кузнецова Е. Своеобразие авторской позиции в цикле очерков И. С. Тургенева «Записки охотника» // Исследователь / Researcher. - М.: МПГУ, 2013. — № 3-4. - С. 296-314.

11. Логутова Н. В. Поэтика пространства и времени романов И. С. Тургенева: дис. ... канд. филол. наук. - Кострома, 2002. - 201 с.

12. Макарова Е. В. Художественное пространство в книге рассказов «Записки охотника» И. С. Тургенева // Вестник Костромского государственного университета им. Н. А. Некрасова. - 2011. - Т. 17. — № 3 - С. 179-182.

13. Петерс А. Роль и функции русской народно-лирической песни в «Записках охотника» И. С. Тургенева // Документальное и художественное в литературном произведении: межвуз. сб. науч. тр. - Иваново, 1994. - C. $18-25$.

14. Плесканюк Т. Н. Номинация цвета в описаниях природы И. С. Тургенева // Филологический аспект: международный научно-практический журнал. — 2015. — № 3 [Электронный ресурс]. — URL: http://scipress.ru/ philology/articles/nominatsiya-tsveta-v-opisaniyakh-prirody-is-turgeneva. html (02.07.2018).

15. Плесканюк Т. Н. Звук и цвет в пейзажах И. С. Тургенева // Слово, высказывание, текст. Сб. науч. тр. I Международной научно-практической конференции. Нижегородский институт управления РАНХиГС. - Нижний Новгород, 2015. - С. 53-56.

16. Рогачева Н. А., Хуэйсинь Цзи. Язык запаха в повести И. С. Тургенева «Вешние воды» // Вестник Тюменского государственного университета. Гуманитарные исследования. Humanitates. - 2017. - T. 3. — № 3. - С. 80-93.

17. Толоконникова И. В. Творческий путь И. С. Тургенева. - М.: МГУ, 2017. $-84 \mathrm{c}$.

18. Топоров В. Н. Странный Тургенев (Четыре главы). - М.: РГГУ, 1998. - 192 с.

19. Турбанов И. С. Поэтика видения в творчестве И. Тургенева // Эволюция форм художественного сознания в русской литературе (опыты феноменологического анализа): сб. науч. тр. - Екатеринбург: Изд-во Урал. ун-та, 2001. - С. 198-232.

20. Фуникова С. В. Проблема полижанровости в «Записках охотника» И. С. Тургенева // Филологические науки. Вопросы теории и практики. - 2015. — № 3 (45). - Ч. III. - С. 176-179.

Информация об авторе: Неминущий Аркадий Николаевич - доктор филологии, профессор кафедры русистики и славистики Даугавпилсского университета.

Дата поступления в редакцию: 08.07.2018

Дата публикаичи: 01.10.2018 


\title{
The Structure and Functions of the Sound Code in the "The Hunting Sketches" by Ivan Turgenev
}

\begin{abstract}
The researchers of Turgenev's writings have gained a significant experience while studying and interpreting the semantics of various components of the artistic world of the writer. For a long time the main accent was focused on the problems of identifying the features of the reconstruction of the heroes and characters of Turgenev's prose. At the same time, in the latter half of the last century considerable efforts were put to determine the place and functions of the space-time structure, its visual segment (including the coloristic one), as well as the peculiarities of the olfaction sphere. However, the role of the sound scores within the boundaries of Turgenev's poetics was studied only sporadically. Meanwhile, the sound code in the "The Hunting Sketches" cycle is of great importance. The structure of this component of the common picture of the world consists of a few levels; each of them has a certain hierarchy inside. At the natural level the sounds of fauna predominate with the predominance of birds' voices, that conveys the semantics of the air and freedom. The noise element of the depicted flora is based on pantheistic principles with an emphasis on aesthetics and metaphorization. Within the social sound code the cultural paradigm occupies a special place with a clearly marked musical-vocal series that results in a special plot with the apogee in the story "Singers". Finally, a number of «mystical» sounds complement the complex picture of the national cosmos, as perceived and portrayed by Turgenev in its prosaic cycle.
\end{abstract}

Keywords: Ivan Turgenev, “The Hunting Sketches”, the nature phonosphere, the sounds of society, the sound code of culture

\section{References}

1. Achkasova G. L. Dialogue of Arts as a Means of Conveying Author's Artistic Individuality: Union of Words and Music in the Works by I. S. Turgenev. In: Uchenye zapiski Rossiyskogo gosudarstvennogo social'nogo universiteta [Scientific Notes of the Russian State Social University], 2011, no. 6, pp. 353357. (In Russ.)

2. Belyaeva I. A. Sistema zhanrov v tvorchestve I. S. Turgeneva [The System of Genres in the Works of I. S. Turgenev]. Moscow, Moscow City University Publ., 2005. 252 p. (In Russ.)

3. Burshtinskaya E. A. Tsvet kak aspekt literaturnogo portreta $v$ khudozhestvennoy proze I. S. Turgeneva: avtoref. dis. ... kand. filol. nauk [Color as an Aspect of the Literary Portrait in I. S. Turgenev's Prose. PhD. philol. sci. diss. abstract]. Cherepovets, 2000. 18 p. (In Russ.) 
4. Bykova O. S. Folk Songs in "The Hunting Sketches" and in the Short Novel “The Lull” by I. S. Turgenev. In: Russkaya rech'. Moscow, Nauka Publ., 2018, no. 1, pp. 107-114. (In Russ.)

5. Gareeva L. N. Functions of the Landscape in the Novels of I. S. Turgenev "Home of the Gentry" and "On the Eve". In: Vestnik Voronezhskogo gosudarstvennogo universiteta. Seriya: Filologiya. Zhurnalistika [Proceedings of Voronezh State University. Series: Philology. Journalism]. Voronezh, 2012, no. 1, pp. 33-39. (In Russ.)

6. Zykhovskaya N. L. The Smell as the Principle of "Artistic Dossier" Prose of Turgenev. In: Put' nauki [The Way of Science]. Volgograd, 2014, no. 6, pp. 63-65. (In Russ.)

7. Zykhovskaya N. L. Ol' faktoriy russkoy prozy XIX veka: dis. ... d-ra filol. nauk [Olfactory Tradition in the Russian Prose of the 19th Century. PhD. philol. sci. diss.]. Yekaterinburg, 2016. 518 p. (In Russ.)

8. Koshelev V. A. The Effect of a Hunter in the Russian Literature of the Middle of the 19th Century. In: I. S. Turgenev. Novye issledovaniya i materialy [I. S. Turgenev. New Research and Materials]. Moscow, St. Petersburg, Al'yansArkheo Publ., 2009, pp. 95-111. (In Russ.)

9. Krivonos V. Sh. The Motif of Knocking in the Poetics of I. S. Turgenev. In: Izvestiya Rossiyskoy Akademii nauk. Seriya literatury i yazyka [The Bulletin of the Russian Academy of Sciences: Studies in Literature and Language], 2000, vol. 59, no. 5, pp. 32-37. (In Russ.)

10. Kuznetsova E. The Originality of the Author's Attitude in the Cycle of Essays by I. S. Turgenev “The Hunting Sketches”. In: Issledovatel' [Researcher]. Moscow, Moscow State Pedagogical University Publ., 2013, no. 3-4, pp. 296-314. (In Russ.)

11. Logutova N. V. Poetika prostranstva i vremeni romanov I. S. Turgeneva: dis. ... kand. filol. nauk [The Poetics of Space and Time in the Novels of I. S. Turgenev. PhD. philol. sci. diss.]. Kostroma, 2002. 201 p. (In Russ.)

12. Makarova E. V. An Artistic Space in the Book of Stories "The Hunting Sketches" by I. S. Turgenev. In: Vesntik Kostromskogo gosudarstvennogo universiteta imeni N. A. Nekrasova [Vestnik of Kostroma State University], 2011, vol. 17, no. 3, pp. 179-182. (In Russ.)

13. Peters A. The Role and Functions of the Russian Folk-Lyric Song in "The Hunting Sketches" by I. S. Turgenev. In: Dokumental'noe i khudozhestvennoe $v$ literaturnom proizvedenii [The Documentary and the Artistic in a Literary Work]. Ivanovo, 1994, pp. 18-25. (In Russ.)

14. Pleskanyuk T. N. The Color Nomination in I. S. Turgenev's Landscape Description. In: Filologicheskiy aspect: mezhdunarodnyy nauchno-prakticheskiy zhurnal [A Philological Aspect: International Scientific and Practical Journal], 2015, no. 3. Available at: http://scipress.ru/philology/articles/nominatsiyatsveta-v-opisaniyakh-prirody-is-turgeneva.html (accessed on July 2, 2018). (In Russ.) 
15. Pleskanyuk T. N. The Sound and the Color in the Landscapes in I. S. Turgenev's Works. In: Slovo, vyskazyvanie, tekst. Sbornik nauchnykh trudov I Mezhdunarodnoy nauchno-prakticheskoy konferentsii [Word, Statement, Text. The Collection of Scientific Papers of the First International Scientific and Practical Conference]. Nizhny Novgorod, 2015, pp. 53-56. (In Russ.)

16. Rogacheva N. A., Khueysin' Tszi. The Language of Smell in the Short Novel “Torrents of Spring” by I. S. Turgenev. In: Vestnik Tyumenskogo gosudarstvennogo universiteta. Gumanitarnye issledovaniya. Humanitates [UT Research Journal. Humanities Research. Humanities], 2017, vol. 3, no. 3, pp. 80-93. (In Russ.)

17. Tolokonnikova I. V. Tvorcheskiy put' I. S. Turgeneva [Turgenev's Artistic Path]. Moscow, Lomonosov Moscow State University Publ., 2017. 84 p. (In Russ.)

18. Toporov V. N. Strannyy Turgenev (Chetyre glavy) [The Strange Turgenev. (Four Chapters)]. Moscow, The Russian State University for the Humanities Publ., 1998. 192 p. (In Russ.)

19. Turbanov I. S. The Poetics of Vision in the Works of I. Turgenev. In: Evolyutsiya form khudozhestvennogo soznaniya v russkoy literature (opyty fenomenologicheskogo analiza) [The Evolution of Forms of Artistic Consciousness in Russian Literature (Experiments of Phenomenological Analysis)]. Yekaterinburg, Ural State University Publ., 2001, pp. 198-232. (In Russ.)

20.Funikova S. V. The Multigenre Problem in "The Hunting Sketches" by I. S. Turgenev. In: Filologicheskie nauki. Voprosy teorii i praktiki [Philological Sciences. Issues of Theory and Practice], 2015, no. 3 (45), part 3, pp. 176-179. (In Russ.)

Information about the author: Neminuscij Arkadij N. - Doctor of Philology, Professor of the Department of Russian Studies and Slavic Studies Daugavpils University.

Received: July 8, 2018

Date of publication: October 1, 2018 